This is a provisional PDF only. Copyedited and fully formatted version will be made available soon.

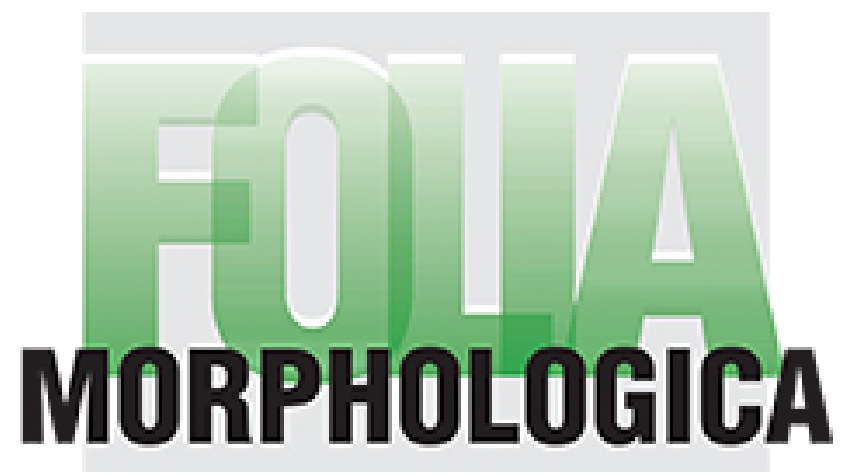

ISSN: 0015-5659

e-ISSN: $1644-3284$

\title{
Quantitative study of the primary ossification center of the parietal bone in the human fetus
}

Authors: M. Grzonkowska, M. Baumgart, M. Badura, M. Wiśniewski, M. Szpinda

DOI: $10.5603 / F M . a 2022.0020$

Article type: Original article

Submitted: $2021-12-22$

Accepted: $2022-01-28$

Published online: 2022-02-28

This article has been peer reviewed and published immediately upon acceptance.

It is an open access article, which means that it can be downloaded, printed, and distributed freely, provided the work is properly cited.

Articles in "Folia Morphologica" are listed in PubMed. 


\title{
Quantitative study of the primary ossification center of the parietal bone in the human
} fetus

M. Grzonkowska et al., Parietal bone ossification

M. Grzonkowska, M. Baumgart, M. Badura, M. Wiśniewski, M. Szpinda

Department of Normal Anatomy, the Ludwik Rydygier Collegium Medicum in Bydgoszcz, the Nicolaus Copernicus University in Torun, Poland

Address for correspondence: Magdalena Grzonkowska, MD, Department of Normal Anatomy, the Ludwik Rydygier Collegium Medicum in Bydgoszcz, ul. Łukasiewicza 1, 85821 Bydgoszcz, Poland, tel.: + 48052 5853705, e-mail: m.grzonkowska@cm.umk.pl

\begin{abstract}
Detailed morphometric data concentrating on the development of primary ossification centers in human fetuses is critical for the early detection of developmental defects. Thus, an understanding of the growth and development of the parietal bone is crucial in assessing both the normal and pathological development of the calvaria. The size of the parietal primary ossification center in 37 spontaneously aborted human fetuses of both sexes (16 males and 21 females) aged 18-30 weeks was studied by means of CT, digital-image analysis and statistics. The numerical data of the parietal primary ossification center in the human fetus displays neither sex nor laterality differences. With relation to fetal age in weeks, the parietal primary ossification center grew in sagittal diameter according to the quadratic function $y=16.322+$ $0.0347 \times(\text { age })^{2} \pm 1.323 \mathrm{R}^{2}=0.96$, in projection surface area according to the cubic function $\mathrm{y}=284.1895+0.051 \times(\text { age })^{3} \pm 0.490$, while in both coronal diameter and volume according to the quartic functions: $\mathrm{y}=21.746+0.000025 \times(\text { age })^{4} \pm 1.256$ and $\mathrm{y}=296.984+0.001 \times$ (age $)^{4}$, respectively. The obtained morphometric data of the parietal primary ossification center may be considered age-specific references, and so may contribute to the estimation of gestational ages and be useful in the diagnostics of congenital cranial defects.
\end{abstract}

Key words: parietal bone, bone development, osteogenesis, fetal development 


\section{INTRODUCTION}

The skull comprises the neurocranium and the viscerocranium or facial skeleton, linked together by sutures, synchondroses and the paired temporomandibular joints [2]. The role of the neurocranium is to protect the brain, while that of the viscerocranium is to protect the sensory and facial organs. The morphogenesis of the bones of calvaria is a long-term developmental process initiated in the early embryogenesis and terminated at adult age [8]. The bones of the cranial vault develop by membranous ossification, while those of the skull base are formed by endochondral ossification. Their fusion into one functional whole refers to different stages of fetal development and after birth. This interaction ensures that the skull growth mechanism, both sutural and cartilaginous, will enable normal growth and development of the brain [9]. The calvaria not only protects the brain, but also constitutes a supportive structure for the face and chewing apparatus functions. However, little is known about mechanical properties and variations of the calvaria [12]. The four borders of the parietal bone are linked to the frontal, temporal, sphenoid, occipital and contralateral parietal bones, thus forming the supero-lateral component of the cranium [11].

The osteogenesis of the cranial vault bones starts with the development of primary ossification centers, specific for each bone. The primary ossification centers appear between weeks 7 and 8 of embryonic life at presumptive bone eminences. Outstandingly, each bone in the calvaria develops from one ossification center except for the parietal bone. At the very beginning the parietal bone originates to ossify from two primary ossification centers which subsequently fuse onto single parietal primary ossification center [10]. The parietal primary ossification center appears at week 8 of gestational age. Afterwards, the ossification process radiates centrifugally toward peripheries of the parietal bone. By week 14 of gestational age, extensive ossification of bilateral parietal bones occurs, which persists along all borders throughout the fetal life. However, cranial sutures adjacent to the parietal bones are relatively wide, particularly in the parieto-temporal region $[8,11]$.

In the human prenatal period is indispensably to assess in utero the fetal skull by routine ultrasound. Abnormalities of the parietal bone development may involve the following defects: craniosynostosis, cranium bifidum, fusion of the parietal foramina, congenital absence of the skull roof, anencephaly or exencephaly [4, 5, 10, 13].

Although the timing of ossification of each cranial bone is relatively well-established, no detailed morphometric measurements involving the use of computed tomography (CT) 
examinations of the parietal primary ossification centers have been reported. To our knowledge, this is the first report in the professional literature to present the morphometric analysis of the parietal primary ossification center in human fetuses grounded in CT imaging.

In the present study we aimed:

- to perform morphometric analysis of the parietal primary ossification center in terms of linear, planar and spatial parameters in human fetuses, so as to determine their normative values;

- to examine possible sex differences for all analyzed parameters, and

- to compute growth dynamics for the analyzed parameters, expressed by best-matched mathematical models.

\section{MATERIALS AND METHODS}

The study material comprised 37 human fetuses of both sexes (16 males and 21 females) aged 18 to 30 weeks of gestation, originating from spontaneous abortions and preterm deliveries. The fetuses were collected before the year 2000 and still remain part of the fetal collection of the Department of Normal Anatomy. The experiment was approved by the Bioethics Committee of Ludwik Rydygier Collegium Medicum in Bydgoszcz (KB 275/2011). The inclusion criteria of investigated fetuses were based on the evaluation of their explicit morphology and statistical cards with the course of pregnancy. Since on macroscopic examination neither internal nor external conspicuous morphological malformations were found, all specimens included in the study were considered normal. Of note, the fetuses did not display any developmental abnormalities of the musculoskeletal system. Fetal ages were determined based on the crown-rump length (CRL) and the known date of the beginning of the last maternal menstrual period. Furthermore, the investigated fetuses could not suffer from growth retardation, as the correlation between the gestational age based on the CRL and that calculated by the last menstruation reached $\mathrm{R}=0.98(\mathrm{p}<0.001)$. Table 1 lists the characteristics of the study group, including age, number and sex of the fetuses.

Using the Siemens-Biograph 128 mCT scanner (Siemens Healthcare GmbH, Erlangen, Germany) located at the Department of Positron Emission Tomography and Molecular Imaging (Oncology Center, the Ludwik Rydygier Collegium Medicum in Bydgoszcz, the Nicolaus Copernicus University Bydgoszcz, Poland), scans of fetuses in DICOM format were attained at $0.4 \mathrm{~mm}$ intervals (Fig. 1). The gray scale of the obtained CT images expressed in Hounsfield units (HU) varied from -275 to -134 for minimum, and from +1165 to +1558 for 
maximum. Therefore, the window width (WW) varied from 1.404 to 1.692, and the window level (WL) varied from +463 to +712 . The specifics of the imaging protocol were as follows: $\mathrm{mAs}-60, \mathrm{kV}-80$, pitch -0.35 , FoV -180 , rot. time -0.5 sec., while those of the CT data were: slice thickness - $0.4 \mathrm{~mm}$, image increment - $0.6 \mathrm{~mm}$, and kernel - B45 f-medium. Measurements of the parietal primary ossification center were done in a specific order (Fig. 2). In each fetus, assessment of the linear parameters, projection surface area and volume of the parietal primary ossification center was carried out. Despite the cartilaginous stage of development, a morphometric analysis regarding their sagittal diameter and volume was feasible, as the contours of the entire bone were already evidently visible [1, 3].

Measurements of the parietal primary ossification center included:

1. coronal (right and left) diameter, based on the determined distance between its proximal and distal borderlines in the sagittal plane (Fig. 2);

2. sagittal (right and left) diameter, based on the determined distance between the anterior and posterior borderlines of the parietal ossification center in the sagittal plane (Fig. 2);

3. projection surface area (right and left), based on the determined contour of the parietal ossification center in the sagittal plane (Fig. 2);

4. volume, calculated using advanced diagnostic imaging tools for 3D reconstruction, taking into account position and the absorption of radiation by a bony tissue (Fig. 1C).

In the present study to analyze all numerical data, we used the Statistica 12.5 and PQStat 1.6.2. programs. Distribution of variables was checked using the Shapiro-Wilk (W) test, while homogeneity of variance was checked using Fisher's test. In order to compare the means, Student's t test for dependent (left-right) and independent (male-female) variables was used. Afterwards, one-way analysis of variance and Tukey's test were used for post-hoc analysis. If no similarity of variance occurred, the non-parametric Kruskal-Wallis test was used. The characterization of developmental dynamics of the analyzed parameters was based on linear and curvilinear regression analyses. The match between the estimated curves and measurement results was evaluated by coefficients of determination $\left(\mathrm{R}^{2}\right)$. Differences were considered statistically significant at $\mathrm{p}<0.05$. The relationship between variables was also estimated with the Pearson correlation coefficient (r).

In an attempt to minimize measurement and observer bias, all measurements were completed by one experienced researcher (M.B.), specializing in image interpretation. Each measurement was reiterated three times under the same conditions but at different times, and then averaged. As shown in Table 2, the intra-class correlation coefficients (ICC) calculated 
on the basis of an observer were statistically significant $(\mathrm{p}<0.001)$ and of excellent reproducibility.

\section{RESULTS}

Mean values and standard deviations of the analyzed parameters of the parietal primary ossification center in human fetuses at analyzed gestational stages have been presented in Tables 3 and 4.

The statistical analysis revealed neither significant sex nor significant laterality differences, which allowed us to compute one growth curve for each analyzed parameter. The growth dynamics expressed in fetal age in weeks were differentiated into quadratic, cubic and quartic functions.

The mean coronal diameter of the parietal primary ossification center in the gestational age range of 18-30 weeks was between $24.60 \pm 0.03 \mathrm{~mm}$ and $41.97 \pm 0.38 \mathrm{~mm}$ on the right, and between $25.51 \pm 0.01 \mathrm{~mm}$ and $42.13 \pm 0.95 \mathrm{~mm}$ on the left, following the quartic function: $\mathrm{y}=21.746+0.000025 \times(\text { age })^{4} \pm 1.256\left(\mathrm{R}^{2}=0.95\right)-($ Fig. 3A $)$.

The mean sagittal diameter of the parietal primary ossification center in the gestational age range of 18-30 weeks was between $28.86 \pm 0.05 \mathrm{~mm}$ and $47.77 \pm 0.35 \mathrm{~mm}$ on the right, and between $29.28 \pm 0.19 \mathrm{~mm}$ and $47.81 \pm 0.31 \mathrm{~mm}$ on the left, in accordance with the quadratic function: $\mathrm{y}=16.322+0.0347 \times(\text { age })^{2} \pm 1.323\left(\mathrm{R}^{2}=0.96\right)-($ Fig. 3B $)$.

The mean projection surface area of the parietal primary ossification center ranged from $631.87 \pm 1.40 \mathrm{~mm}^{2}$ at 18 weeks of gestation to $1721.56 \pm 23.30 \mathrm{~mm}^{2}$ at 30 weeks of gestation on the right, and from $664.68 \pm 4.23 \mathrm{~mm}^{2}$ to $1732.25 \pm 48.35 \mathrm{~mm}^{2}$, respectively, on the left, and modelled the cubic function: $\mathrm{y}=284.1895+0.051 \times(\text { age })^{3} \pm 0.490\left(\mathrm{R}^{2}=0.94\right)-$ (Fig. 3C).

The mean volume of the parietal primary ossification center in the gestational age range of 18-30 weeks was between $429.67 \pm 1.11 \mathrm{~mm}^{3}$ and $1224.06 \pm 19.51 \mathrm{~mm}^{3}$ on the right, and between $451.98 \pm 2.88 \mathrm{~mm}^{3}$ and $1229.90 \pm 34.33 \mathrm{~mm}^{3}$ on the left, following the quartic function: $\mathrm{y}=296.984+0.001 \times(\text { age })^{4} \pm 6.971\left(\mathrm{R}^{2}=0.94\right)-($ Fig. 3D $)$.

\section{DISCUSSION}

The ossification process of the parietal bone begins at 7-8 weeks of embryonic life, and is followed by extensive ossification at week 14, which determines the normal development of the neurocranium until birth. In neonates the neurocranial volume is $60 \%$ of 
adult size, while the viscerocranial volume is $40 \%$. The height of the neurocranium is $60 \%$ of the total height of a newborn's skull and $40 \%$ of that of an adult's skull [9].

To our knowledge, this paper is the first literature report to quantitatively concentrate on morphometric analysis of the parietal primary ossification center in human fetuses using CT and, concurrently, its growth dynamics. Previous studies have included only measurements and growth analysis with the development of mathematical growth models for macerated skulls.

Zhang et al. [14] measured the parietal primary ossification center in 180 human fetuses aged 5 to 38 weeks of gestation and found the parietal ossification to start at week 9 of gestational age from a single ossification center in the presumptive parietal eminence. According to these authors, in fetuses aged 9-37 weeks its sagittal and coronary diameters ranged from $2.10-3.50$ to $83.28-87.07 \mathrm{~mm}$ and from $2.10-3.80$ to $80.53-84.85 \mathrm{~mm}$, correspondingly. This was modelled by the following linear functions: $y=-20.568+2.9676 \times$ age for sagittal diameter, and $y=-15.709+2.7924 \times$ age for coronary diameter.

In our study, an intensive increase in all parameters tested was observed in the analyzed period from 18 to 30 weeks of gestational age, with functions of age from a quadratic function through a cubic function to quartic functions.

The growth dynamics for sagittal diameter displayed the quadratic function $y=16.322$ $+0.0347 \times(\text { age })^{2} \pm 1.323$, while that for projection surface area demonstrated the cubic function $\mathrm{y}=284.1895+0.051 \times(\text { age })^{3} \pm 0.490$.

The coronal diameter and volume of the parietal primary ossification center followed quadratic functions $\mathrm{y}=21.746+0.000025 \times(\text { age })^{4} \pm 1.256$ and $\mathrm{y}=296.984+0.001 \times(\text { age })^{4}$ \pm 6.971 , respectively.

Our literature review revealed the quantitative assessment of the neurocranial ossification centers using CT to be performed by our team only for the occipital and frontal bones in the fetus.

In our study devoted to the development of the primary ossification center of the occipital squama in human fetuses, the developmental dynamics of the coronal diameter followed the linear functions: $y=-6.462+1.109 \times$ age \pm 0.636 on the right, and $y=-9.395+$ $1.243 \times$ age \pm 0.577 on the left. The transverse diameters of the supraoccipital and interparietal parts as well as projection surface area of the occipital squama ossification center increased in relation to gestational age expressed in weeks, following the logarithmic functions: $\mathrm{y}=-98.232+39.663 \times \ln ($ age $) \pm 0.721, y=-79.903+32.107 \times \ln ($ age $) \pm 0.974, y$ $=-3062.89+1108.98 \times \ln ($ age $) \pm 29.476$, respectively. The volume of the occipital squama 
ossification center increased proportionately to the quadratic function: $y=-330.105+1.554 \times$ age $^{2} \pm 32.559[7]$.

Furthermore, in our study of the development of the frontal squama ossification center in human fetuses, the growth dynamics for its coronal diameter, projection surface area and volume followed the quadratic functions: $y=13.756+0.021 \times$ age $^{2} \pm 0.024, y=38.285+$ $0.889 \times$ age $^{2} \pm 0.034$, and $y=-90.020+1.375 \times$ age $^{2} \pm 11.441$, respectively. However, the transverse diameter increased proportionately to gestational age alone, following the linear function: $\mathrm{y}=0.956+0.956 \times$ age $\pm 0.823[6]$.

Unfortunately, a lack of numerical data concerning the parietal primary ossification center in the medical literature limits a more detailed discussion on this topic.

The development of the parietal bone is highly variable. There are reports in the professional literature that the prolonged ossification of the posterior parietal region in the vicinity of the obelion point may lead to the formation of a V-shaped notch named the subsagittal suture of Pozzi and pars obelica. Knowledge of the variability of the parietal bone ossification allows a much better understanding of the formation of the sagittal suture near the obelion point. The formation of the sagittal suture occurs through the closure of 3 fontanelles, i.e. the anterior fontanelle located between the frontal squama and bilateral parietal bones, the posterior fontanelle sited between the parietal bones and occipital squama and the obelic fontanelle or sagittal fontanelle that occurs in $50-80 \%$ of cases and contributes to the formation of unilateral or bilateral parietal foramina. The obelic fontanelle usually closes in the first two years of life, and variations in the degree of its closure may result in obelic bones, an accessory parietal emissary foramen, enlarged parietal foramen and the parietal fissure [11].

Understanding the development of the parietal bone in human fetuses is necessary for diagnosing skeletal dysplasias or detecting anomalies of the calvaria. Craniosynostosis is a congenital malformation with its incidence estimated at around 5 per 10,000 live births. It represents a condition, in which a permanent connection among the calvarial bones is formed prematurely. This puts the continued growth of the brain and head in the wrong direction, resulting in deformation, sometimes causing severe damage to the brain due to increased intracranial pressure. Craniosynostosis can be isolated or as a component of various congenital defects, e.g. Apert and Crouzon syndromes [4, 13].

Another aberration is cranium bifidum or "skull cleft", which forms due to the abnormal closure of the skull in the same way as its medullary counterpart, spina bifida. Cranium bifidum occultum is a rare disease with its incidence of 1-3 per 10,000 births 
involving delayed ossification of the parietal bone resulting in medially located skull roof foramina, with the scalp, periosteum and dura mater being intact. This is usually the mildest type of neural tube defects because there is no cerebral herniation, and the skull defects often close over time. The disease is generally asymptomatic, but it should be emphasized that the persistent bone defects cause the brain to be unprotected and prone to injuries [10].

Furthermore, cranium bifidum may be accompanied by dysplasias of the viscerocranium, affecting the structure of the medial line of the head and face, such as frontonasal dysplasia [10].

Another set of defects involving the parietal bones is a fusion of parietal foramina, i.e. occurrence of holes in the posterosuperior angles of the parietal bones, by which emissary veins pass through the calvaria. In this defect, the scalp remains intact, and the size of deficiencies decreases as the child ages [10]. Another ossification disturbance in the parietal bone is exemplified by enlarged parietal foramina, occurring due to insufficient ossification around them [5]. Other important defects involving the parietal bone include: cranium bifidum with meningeal or cerebral herniation passing through the hole in the skull, acalvaria - a congenital lack of cranial roof, acrania - a lack of cranial roof and cerebral tissue, and exencephaly - a serious deformation and exposure of the brain which is outside the skull because of the lack of scalp and calvaria [10].

To our opinion, the main limitation of this study is a relatively narrow gestational age group, ranging from 18 to 30 weeks, and a small number of cases, including 37 human fetuses.

\section{CONCLUSIONS}

1. The morphometric parameters of the parietal primary ossification center display neither sex nor laterality differences.

2. With relation to fetal age in weeks, the parietal primary ossification center grows in sagittal diameter according to a quadratic function, in projection surface area according to a cubic function, while in both coronal diameter and volume according to quartic functions. 3. The obtained morphometric data of the parietal primary ossification center may be considered age-specific references, and so may contribute to the estimation of gestational ages and be useful in the diagnostics of congenital cranial defects.

Conflict of interest: None declared 


\section{REFERENCES}

1. Chano T, Matsumoto K, Ishizawa M, Morimoto S, Hukuda S, Okabe H, Kato H, Fujino S. Analysis of the presence of osteocalcin, S-100 protein, and proliferating cell nuclear antigen in cells of various types of osteosarcomas. Eur J Histochem. 1996; 40: 189-198.

2. Chmielewski JJ. New terminologia anatomica: cranium and extracranial bones of the head. Folia Morphol. 2021; 80(3): 477-486, doi: 10.5603/FM.a2019.0129.

3. Duarte WR, Shibata T, Takenaga K, Takahashi E, Kubota K, Ohya K, Ishikawa I, Yamauchi M, Kasugai S. S100A4: a novel negative regulator of mineralization and osteoblast differentiation. J Bone Miner Res. 2003; 18: 493-501, doi: 10.1359/jbmr.2003.18.3.493.

4. Esteve-Altava B, Vallès-Català T, Guimerà R, Sales-Pardo M, Rasskin-Gutman D. Bone fusion in normal and pathological development is constrained by the network architecture of the human skull. Scientific Reports. 2017; 1609.07462v2(1), doi: 10.1038/s41598-01703196-9.

5. Griessenauer ChJ, Veith P, Mortazavi MM, Stewart C, Grochowsky A, Loukas M, Tubbs RS. Enlarged parietal foramina: a review of genetics, prognosis, radiology, and treatment. Childs Nerv Syst. 2013; 29(4): 543-547, doi: 10.1007/s00381-012-1982-7.

6. Grzonkowska M, Baumgart M, Badura M, Wiśniewski M, Szpinda M. Morphometric study of the primary ossification center of the frontal squama in the human fetus. Surg Radiol Anat. 2020; 42(7): 733-740, doi: 10.1007/s00276-020-02425-7.

7. Grzonkowska M, Baumgart M, Badura M, Wiśniewski M, Szpinda M. Quantitative anatomy of the fused ossification center of the occipital squama in the human fetus. PLoS One. 2021; 23;16(2):e0247601, doi: 10.1371/journal.pone.0247601.

8. Jin SW, Sim KB, Kim SD. Development and growth of the normal cranial vault: an embryologic review. J Korean Neurosurg Soc. 2016; 59(3): 192-196, doi: 10.3340/jkns.2016.59.3.192.

9. Kulewicz M. Craniofacial growth and development. Acta Clinica. 2002; 2(2): 168-178.

10. Moreno VGF, del Río MMA, Coruñ MCM, Souza MR, Gálvez CAA. Cranium bifidumoccultum with severe hypoplasia of parietal bones associate to corpus callosum agenesis and seizures. J Med Res. 2017; 3(4): 180-182. 
11. Murlimanju BV, Saralaya VV, Somesh MS, Prabhu LV, Krishnamurthy A, Chettiar GK, Pai MM. Morphology and topography of the parietal emissary foramina in South Indians: an anatomical study. Anat Cell Biol. 2015; 48: 292-298, doi: 10.5115/acb.2015.48.4.292.

12. Peterson J, Dechow PC. Material properties of the inner and outer cortical tables of the human parietal bone. Anat Rec. 2002; 268: 7-15, doi: 10.1002/ar.10131.

13. Rice DPC, Rice R, Thesleff I. Molecular mechanisms in calvarial bone and suture development, and their relation to craniosynostosis. Eur J Orthod. 2003; 25: 139-148, doi: 10.1093/ejo/25.2.139.

14. Zhang W, Wang J, Wang W. Development and measurement of fetal parietal ossification. Advances in Computer Science Research. 2015; https://doi.org/10.2991/iccse-15.2015.75.

Table 1. Age, number and sex of the fetuses studied

\begin{tabular}{|c|c|c|c|c|c|c|c|}
\hline \multirow{2}{*}{$\begin{array}{l}\text { Gestational } \\
\text { age }\end{array}$} & \multicolumn{4}{|c|}{ Crown-rump length (mm) } & \multirow{2}{*}{$\begin{array}{l}\text { No. of } \\
\text { fetuses } \\
\mathbf{N} \\
\end{array}$} & \multicolumn{2}{|c|}{ Sex } \\
\hline & Mean & SD & Min. & Max. & & $0^{x}$ & q \\
\hline 18 & 133.33 & 5.77 & 130.00 & 140.00 & 3 & 1 & 2 \\
\hline 19 & 146.50 & 2.89 & 143.00 & 150.00 & 4 & 2 & 2 \\
\hline 20 & 161.00 & 2.71 & 159.00 & 165.00 & 4 & 2 & 2 \\
\hline 21 & 173.67 & 2.31 & 171.00 & 175.00 & 3 & 2 & 1 \\
\hline 22 & 184.67 & 1.53 & 183.00 & 186.00 & 3 & 1 & 2 \\
\hline 23 & 198.67 & 2.89 & 197.00 & 202.00 & 3 & 1 & 2 \\
\hline 24 & 208.00 & 3.56 & 205.00 & 213.00 & 4 & 1 & 3 \\
\hline 25 & 214.00 & & 214.00 & 214.00 & 1 & 0 & 1 \\
\hline 26 & 229.00 & 5.66 & 225.00 & 233.00 & 2 & 1 & 1 \\
\hline 27 & 240.33 & 1.15 & 239.00 & 241.00 & 3 & 3 & 0 \\
\hline 28 & 249.50 & 0.71 & 249.00 & 250.00 & 2 & 0 & 2 \\
\hline 29 & 253.00 & 0.00 & 253.00 & 253.00 & 2 & 0 & 2 \\
\hline 30 & 262.67 & 0.58 & 262.00 & 263.00 & 3 & 2 & 1 \\
\hline Total & & & & & 37 & 16 & 21 \\
\hline
\end{tabular}

Table 2. Intra-class correlation coefficients (ICC) values for inter-observer recurrence

\begin{tabular}{ll}
\hline Parameter & ICC \\
\hline Right coronal diameter & $0.998 *$
\end{tabular}

Right coronal diameter $\quad$ 0.998* 


\begin{tabular}{lc} 
Left coronal diameter & $0.997^{*}$ \\
Right sagittal diameter & $0.998^{*}$ \\
$\begin{array}{l}\text { Left sagittal diameter } \\
\begin{array}{l}\text { Left projection surface } \\
\text { area }\end{array}\end{array}$ & $0.998^{*}$ \\
$\begin{array}{l}\text { Right projection surface } \\
\text { area }\end{array}$ & $0.996^{*}$ \\
$\begin{array}{l}\text { Right volume } \\
\text { Left volume }\end{array}$ & $0.998^{*}$ \\
\hline $\begin{array}{l}\text { Intra-class correlation coefficients marked with } \\
*\end{array}$ & $0.997^{*}$ \\
\hline
\end{tabular}

Table 3. Coronal and sagittal diameters, projection surface area and volume of the right ossification center of the parietal bone in human fetuses

\begin{tabular}{|c|c|c|c|c|c|c|c|c|c|}
\hline \multirow{3}{*}{$\begin{array}{l}\text { Gestationa } \\
\text { l age } \\
\text { (weeks) }\end{array}$} & \multirow{3}{*}{$\begin{array}{l}\text { Numbe } \\
\text { r of } \\
\text { fetuses }\end{array}$} & \multicolumn{8}{|c|}{ Ossification center of the right parietal bone } \\
\hline & & \multicolumn{2}{|c|}{$\begin{array}{l}\text { coronal } \\
\text { diameter }(\mathrm{mm})\end{array}$} & \multicolumn{2}{|c|}{$\begin{array}{l}\text { sagittal } \\
\text { diameter }(\mathrm{mm})\end{array}$} & \multicolumn{2}{|c|}{$\begin{array}{l}\text { projection surface } \\
\text { area }\left(\mathrm{mm}^{2}\right)\end{array}$} & \multicolumn{2}{|c|}{ volume $\left(\mathrm{mm}^{3}\right)$} \\
\hline & & Mean & SD & Mean & SD & Mean & SD & Mean & SD \\
\hline 18 & 3 & 24.60 & 0.03 & 28.86 & 0.05 & 631.87 & 1.40 & 429.67 & 1.11 \\
\hline 19 & 4 & 25.40 & 0.37 & 29.61 & 0.34 & 669.30 & 17.43 & 455.15 & 11.88 \\
\hline 20 & 4 & 26.10 & 0.18 & 30.08 & 0.07 & 707.76 & 15.09 & 487.58 & 7.59 \\
\hline 21 & 3 & 26.51 & 0.02 & 30.32 & 0.12 & 736.30 & 9.85 & 521.34 & 2.46 \\
\hline 22 & 3 & 26.67 & 0.10 & 31.15 & 0.57 & 774.79 & 20.49 & 523.27 & 16.08 \\
\hline 23 & 3 & 27.00 & 0.10 & 33.48 & 1.26 & 808.87 & 7.90 & 570.68 & 40.87 \\
\hline 24 & 4 & 28.08 & 0.62 & 35.50 & 0.39 & 877.22 & 28.74 & 640.37 & 20.98 \\
\hline 25 & 1 & 29.10 & & 36.40 & & 932.13 & & 680.46 & \\
\hline 26 & 2 & 31.45 & 0.07 & 38.75 & 0.07 & 1048.07 & 4.27 & 765.09 & 3.12 \\
\hline 27 & 3 & 34.17 & 0.38 & 41.47 & 0.38 & 1218.51 & 24.69 & 865.14 & 17.53 \\
\hline 28 & 2 & 38.35 & 0.21 & 45.65 & 0.21 & 1505.60 & 15.32 & 1068.98 & 10.88 \\
\hline 29 & 2 & 39.45 & 0.92 & 46.65 & 0.78 & 1586.45 & 48.15 & 1123.93 & 44.92 \\
\hline 30 & 3 & 41.97 & 0.38 & 47.77 & 0.35 & 1721.56 & 23.30 & 1224.06 & 19.51 \\
\hline
\end{tabular}

Table 4. Coronal and sagittal diameters, projection surface area and volume of the left ossification center of the parietal bone in human fetuses

\begin{tabular}{|c|c|c|c|c|c|}
\hline \multirow{3}{*}{$\begin{array}{l}\text { Gestational } \\
\text { age } \\
\text { (weeks) }\end{array}$} & \multirow{3}{*}{$\begin{array}{l}\text { Number } \\
\text { of } \\
\text { fetuses }\end{array}$} & \multicolumn{4}{|c|}{ Ossification center of the left parietal bone } \\
\hline & & $\begin{array}{l}\text { coronal } \\
\text { diameter }(\mathrm{mm})\end{array}$ & $\begin{array}{l}\text { sagittal diameter } \\
(\mathbf{m m})\end{array}$ & $\begin{array}{l}\text { projection surface } \\
\text { area }\left(\mathrm{mm}^{2}\right)\end{array}$ & Jl \\
\hline & & Mean & Mean & Mean & Mean \\
\hline
\end{tabular}




\begin{tabular}{llllllllll}
18 & 3 & 25.51 & 0.01 & 29.28 & 0.19 & 664.68 & 4.23 & 451.98 & 2.88 \\
19 & 4 & 26.03 & 0.41 & 29.90 & 0.34 & 692.59 & 18.43 & 470.96 & 12.53 \\
20 & 4 & 26.90 & 0.17 & 30.37 & 0.08 & 743.36 & 6.63 & 524.17 & 25.62 \\
21 & 3 & 27.35 & 0.12 & 30.63 & 0.12 & 765.16 & 10.00 & 550.92 & 7.20 \\
22 & 3 & 27.52 & 0.09 & 31.46 & 0.57 & 796.55 & 16.93 & 549.04 & 30.35 \\
23 & 3 & 27.80 & 0.12 & 33.79 & 1.26 & 864.49 & 35.66 & 561.92 & 23.18 \\
24 & 4 & 28.61 & 0.65 & 35.75 & 0.32 & 956.52 & 36.01 & 621.74 & 23.41 \\
25 & 1 & 29.51 & & 36.24 & & 1005.28 & & 653.43 & \\
26 & 2 & 31.17 & 1.64 & 37.89 & 1.63 & 1060.94 & 34.68 & 689.61 & 22.54 \\
27 & 3 & 34.06 & 1.42 & 40.77 & 1.42 & 1195.58 & 80.10 & 760.49 & 44.17 \\
28 & 2 & 37.33 & 2.55 & 44.04 & 2.55 & 1416.64 & 78.14 & 934.98 & 47.57 \\
29 & 2 & 39.58 & 0.21 & 46.29 & 0.21 & 1575.68 & 15.67 & 1118.73 & 11.12 \\
30 & 3 & 42.13 & 0.95 & 47.81 & 0.31 & 1732.25 & 48.35 & 1229.90 & 34.33 \\
\hline
\end{tabular}

Figure 1. A male human fetus aged 20 weeks in the sagittal projection (A), its skeletal reconstruction in the sagittal projection (B), 3D reconstruction of the parietal primary ossification center (C) using Osirix 3.9 MD.

Figure 2. Measurement scheme of the parietal primary ossification center: 1 - coronal diameter, 2 - sagittal diameter, 3 - projection surface area.

Figure 3. Regression lines for coronal diameter (A), sagittal diameter (B), projection surface area $(\mathbf{C})$, and volume $(\mathbf{D})$ of the parietal primary ossification center. 


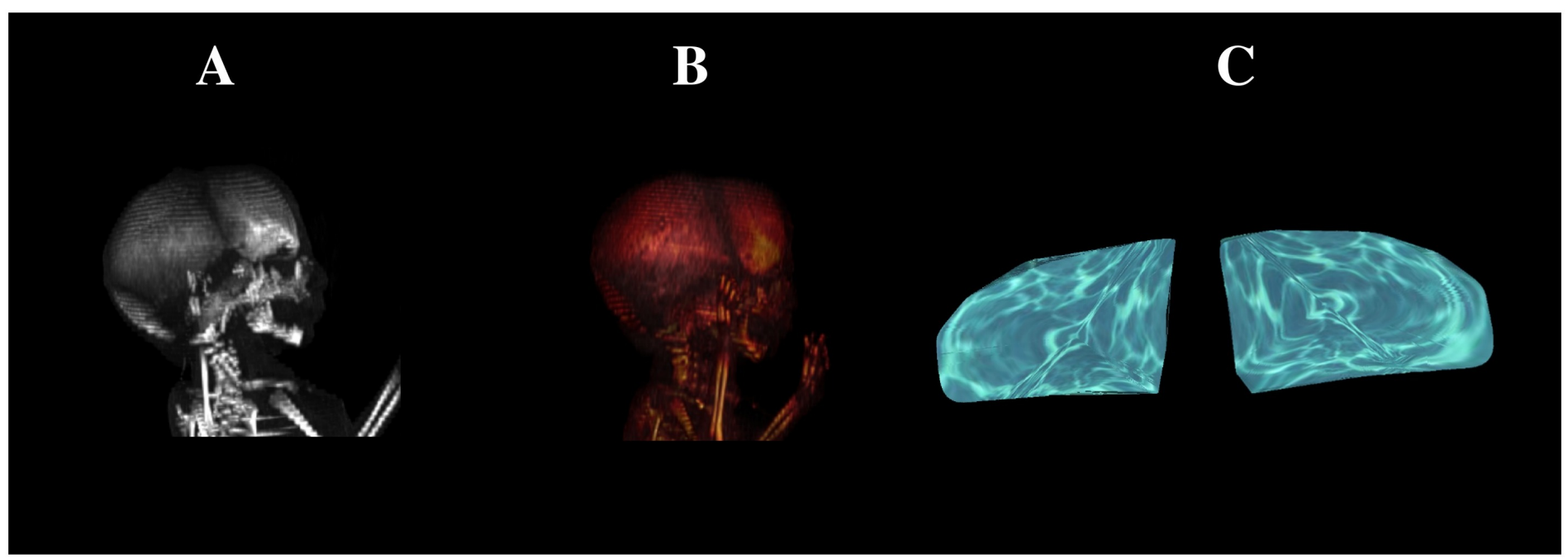



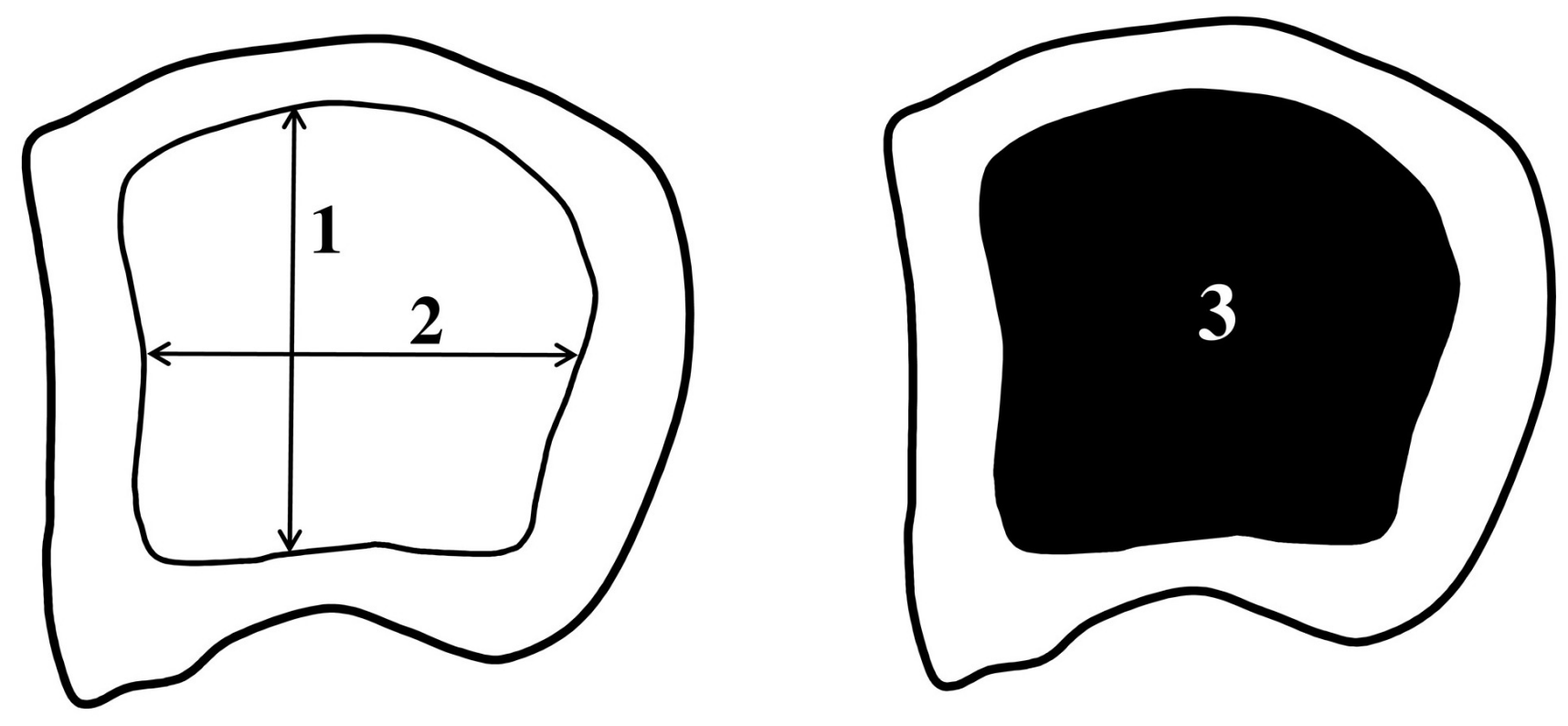

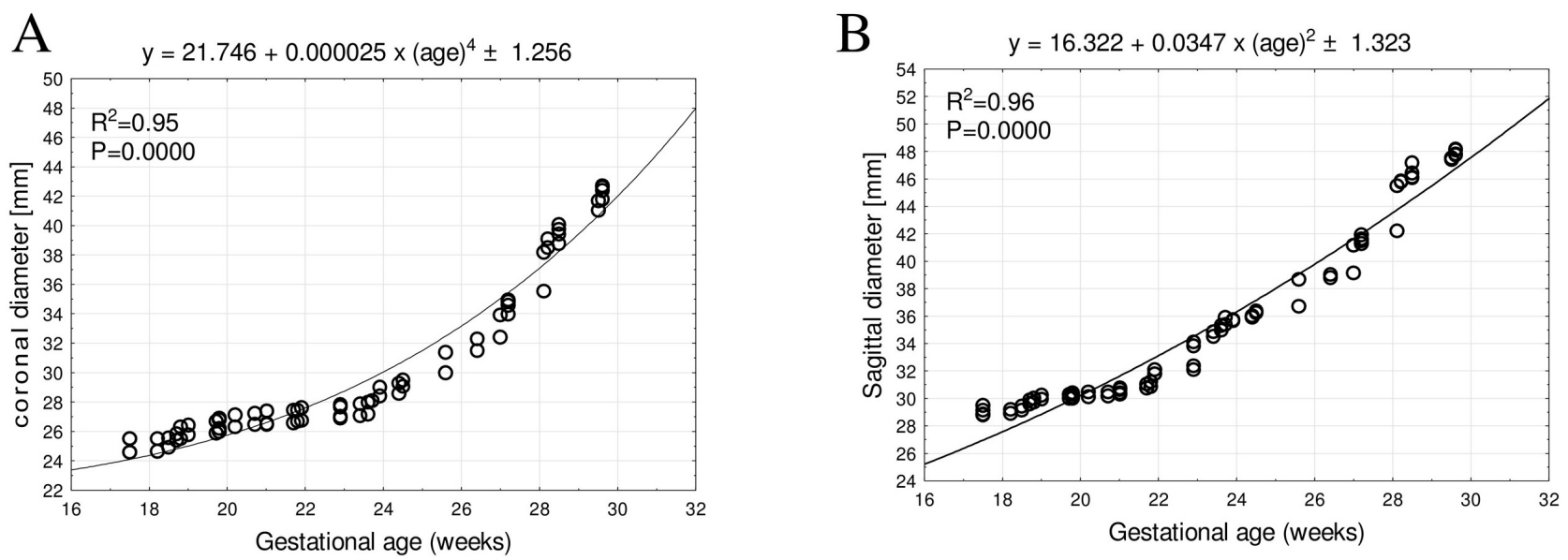

C

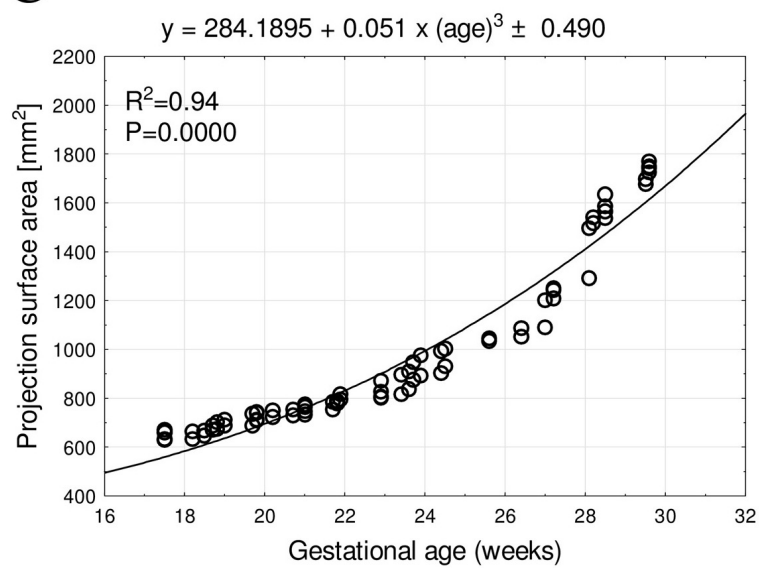

D

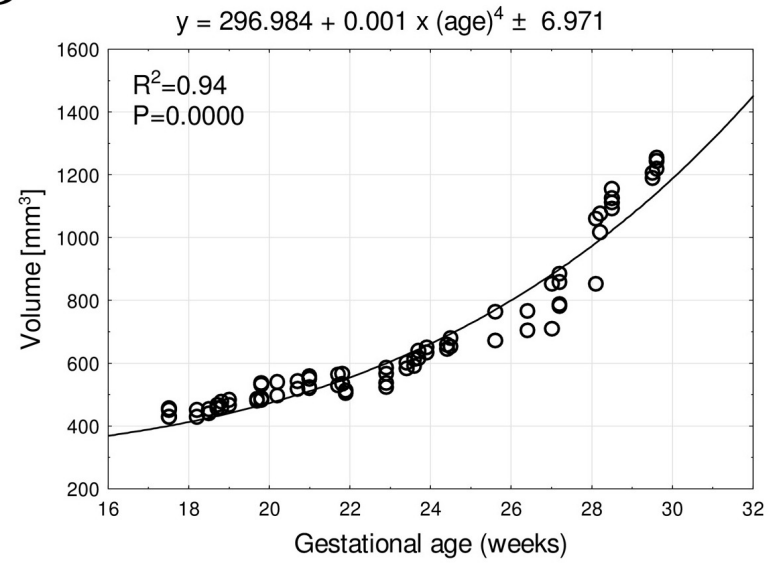

